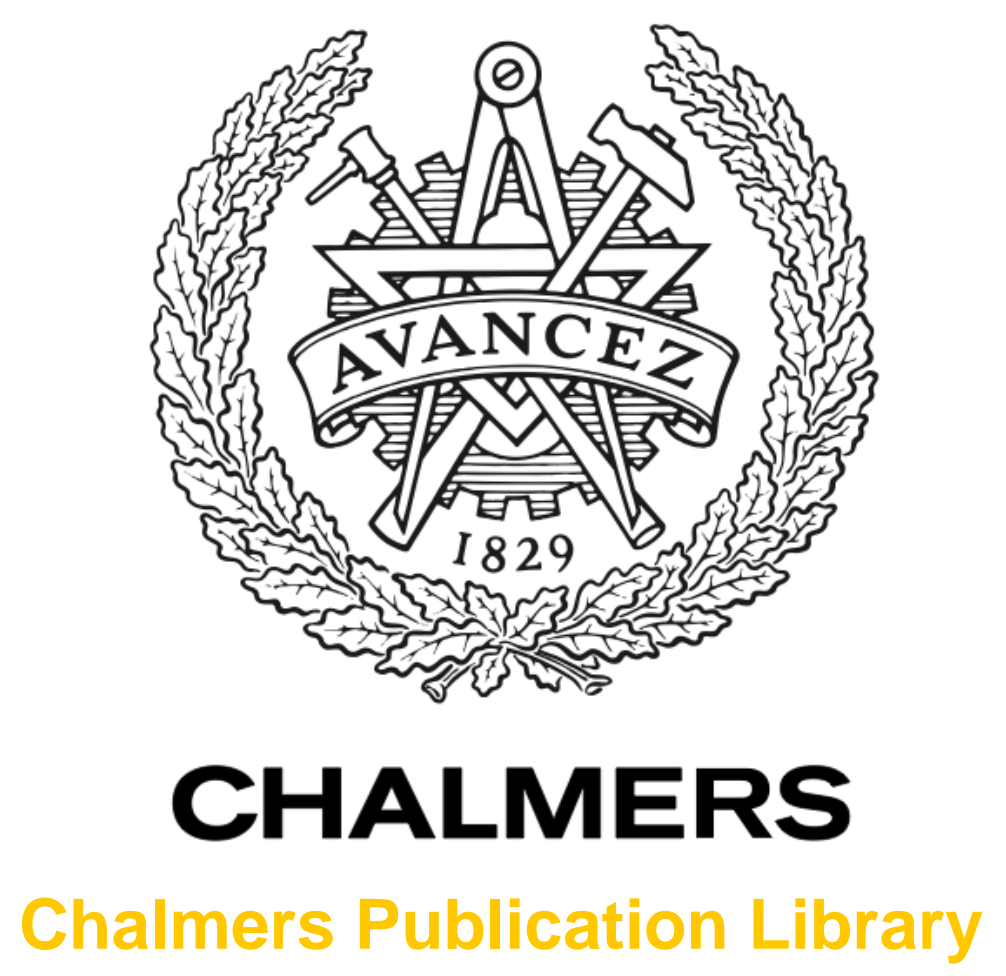

Reinforcing tailor-made concrete structures: Alternatives and challenges

This document has been downloaded from Chalmers Publication Library (CPL). It is the author's version of a work that was accepted for publication in:

Engineering Structures (ISSN: 0141-0296)

Citation for the published paper:

Fall, D. ; Lundgren, K. ; Rempling, R. et al. (2012) "Reinforcing tailor-made concrete structures: Alternatives and challenges". Engineering Structures, vol. 44 pp. 372-378.

http://dx.doi.org/10.1016/j.engstruct.2012.06.003

Downloaded from: http://publications.lib.chalmers.se/publication/165192

Notice: Changes introduced as a result of publishing processes such as copy-editing and formatting may not be reflected in this document. For a definitive version of this work, please refer to the published source. Please note that access to the published version might require a subscription. 


\title{
Reinforcing tailor-made concrete structures: Alternatives and challenges
}

\author{
David Fall ${ }^{\mathrm{a}, *}$, Karin Lundgren ${ }^{\mathrm{a}}$, Rasmus Rempling ${ }^{\mathrm{a}}$, Kent Gylltoft ${ }^{\mathrm{a}}$ \\ ${ }^{a}$ Department of Civil and Environmental Engineering, Division of Structural Engineering, \\ Chalmers University of Technology, \\ Sven Hultins gata 8, 41258 Göteborg, Sweden
}

\begin{abstract}
Recent advances in automated concrete production make it possible to produce geometrically complex concrete structures. The purpose of this paper is to review reinforcement alternatives suitable for such structures and to analyse the problems associated with the geometrical complexity, not only in the reinforcement itself, but also in design. A review of the literature on reinforcement alternatives and governing standards shows that conventional steel reinforcement load bearing structures cannot easily be set aside. Any deviation from the standard structural elements, e.g. beams, walls and slabs, introduces design problems for most structural engineers. Approaches to problems of this complex nature are discussed here. Further developments needed are indicated: being able to choose the reinforcement direction, and optimization with regard to parameters other than the reinforcement amount, e.g. feasibility of production. Furthermore, the need for a rational design process is discussed and some key issues, such as software incompatibilities are raised.
\end{abstract}

Keywords: Complex shaped concrete, Alternative reinforcement, Reinforcement design, Concrete shell design

\section{Introduction}

The formability of concrete is a greatly appreciated feature used in modern architecture. By automation of the production process, this formability could be more widely used. However, the automated production of concrete elements is a general expression covering everything from machinery performing single production steps to advanced fully automated systems, for example producing façade elements or concrete bricks. Most of the automated production seen today is developed for large production series. Each machine is designed and programmed to perform a few steps in the production, e.g. reinforcement bending or welding. Generally, these machines only produce one type of element with very limited variations between series. A European project, TailorCrete (www.tailorcrete.com),

${ }^{*}$ Corresponding author. Tel.: +4631 772 2248; fax: +46317722260

Email address: david.fall@chalmers.se (David Fall) 
targets the general automation of all steps from a 3D model to finalized concrete structures. Such a general solution would allow unique elements to be produced while retaining the economic benefits of large scale automated production; hence, tailor-made concrete structures could be used more commonly than they are today, instead of being limited to prestigious projects.

When discussing complex shape in modern construction, shells are often of interest. The ideal shell is shaped in such a way that the concrete acts in pure compression, utilizing the strength fully. The project TailorCrete aims to construct load-bearing structures in any geometry, i.e. not only the perfect shell; hence, reinforcement is needed in order to enhance the tensile strength of the concrete composite. In the first part of this paper a variety of reinforcement alternatives are described and discussed from the viewpoint of automated production of tailor-made concrete structures.

Furthermore, the geometrical complexity of the tailor-made concrete structures will introduce a design challenge for the structural engineer in almost every single case. Hence, there is a need for a rational, at least semi-automatic, design procedure. In Sections 3 and 4 the necessity of a rational design process is discussed and a theoretical background for reinforcement design is given, respectively.

\section{Reinforcement in tailor-made concrete structures}

The relatively high compressive stress capacity of concrete is well-known and is the main reason for the wide use of concrete as a building material. However, tensile stress and shrinkage tend to cause cracks in the unreinforced material. Therefore, reinforcement is used to provide structural integrity after cracking. In this study four reinforcement alternatives were investigated in order to evaluate which ones are suitable for automated production of geometrically complex structures. Conventional steel reinforcement has been widely used during the past century. In recent decades many alternatives or complements have been developed, e.g. fibre reinforcement, fibre reinforced polymer bars and textile reinforcement.

Conventional reinforcement provides a concrete element with high loading capacity and a well-established design procedure. Thereby, the use of conventional steel reinforcement simplifies the implementation of tailor-made concrete elements with regard to regulations and standards. It is, however, important to stress that the need for development of the production method is pressing. To fulfil the project aims, the reinforcement bars must be formed, in an automated fashion, in arbitrary geometries and assembled with sufficient precision and robustness. Such aspects are currently researched at the University of Southern Denmark and the results so far seem promising [1].

Fibre reinforcement is often described as short discontinuous fibres of varying length, thickness and material. Reinforcing fibres can be made of steel, glass, various synthetic materials (such as coal or polymer) or organic materials. Steel fibres can be used as primary reinforcement and they have good durability with regard to corrosion. Glass fibres are most commonly used in thin, non-structural, concrete elements, e.g. façade

elements. The tensile strength of glass fibres is very high; however, it is greatly affected 
by deterioration [2]. Synthetic fibres can be produced from several materials with widely differing properties e.g. polyethylene, polypropylene, coal and aramid. The main benefit of using fibre reinforcement is that it offers a simple and rational production process well suited for application in concrete elements of complex shape. Fibre reinforcement is mainly used as secondary reinforcement. However, in some applications it has been used as a primary reinforcement with good results [3]. Further research is needed for such use to be extended. Furthermore, it is desirable to distribute and orient the fibres throughout the concrete structure in order to improve and optimize the reinforcing effect.

Bars made of fibre reinforced polymers (FRP bars) can be a good alternative in tailormade concrete structures, especially in thin parts where the concrete cover required for conventional reinforcement cannot be fulfilled. The FRP bars are made by continuous aramid, coal or glass fibres incorporated in a polymer matrix (e.g. polyester, epoxy or vinyl ester). The properties of the composite are affected by the fibre and matrix materials; they are generally characterized by lower weight, lower elastic modulus and higher tensile strength than conventional steel reinforcement. Although FRP does not corrode, other deteriorating mechanisms affect the composite. Sea salt, de-icing salt, freeze-thaw cycles, UV light and fresh water can all influence the durability, as reported by Dejke [4. The coefficient of thermal expansion is, in contrast to conventional steel reinforcement, differing from that of concrete. This can lead to restraint forces in the composite structure [5]. In general the fracture is brittle; however, a more ductile material behaviour can be obtained by combining several fibre materials within the matrix [5. The composite behaviour under fire needs to be carefully considered in design as FRP systems are sensitive to fire [6]. Furthermore, a major disadvantage of FRP bars is the generally limited formability, i.e. the composite cannot be reshaped.

Textile reinforcement is made of continuous fibres arranged in several directions (e.g. nets). In these textiles, the fibre material is more effectively utilized than if the same material is scattered randomly in the concrete, as is common for fibre reinforced concrete [7]. However, the production and application processes are very complex. Common fibre materials are AR glass, coal and aramid, although thin steel or polymer threads can also be used. The textile composites can be produced through hand lay-up, pultrusion or extrusion. While hand lay-up is a manual craftsmanship based production, pultrusion and extrusion techniques are more suitable for industrial production with large series. Depending on the textile type and the production method specific requirements are sat on the concrete mix design, limiting the possible choices. Textile reinforcement offers great flexibility and could therefore be regarded as an alternative for tailor-made concrete elements; however, the production methods used today require extensive development before they can be implemented in a fully automated production process.

Moreover, it should be mentioned that many of the alternatives presented can be used in combination, e.g. conventional steel reinforcement and fibre reinforcement or combinations of fibres of different materials [8]. The advantages and disadvantages identified for the reinforcement types discussed are summarized in Table 1. In this table all types of fibre materials are generalized under the category fibre reinforcement. As mentioned, the fibre material influences the composite behaviour; however, the general features tabulated in 
Table 1 are common for all fibre materials. Advantages and disadvantages with different fibre materials are summarized in Table 2. More background on this table can be found in Fall and Nielsen [9].

Table 1: Summary of the advantages and disadvantages of four reinforcement systems.

\begin{tabular}{|c|c|c|}
\hline & + & - \\
\hline Conventional reinforcement steel & $\begin{array}{l}\text { Provides structural } \\
\text { integrity. } \\
\text { Widely used, i.e. easy to } \\
\text { implement with regard } \\
\text { to guidelines and design } \\
\text { codes. } \\
\text { Thermal expansion } \\
\text { normally equal to that } \\
\text { of concrete. } \\
\text { Inexpensive. }\end{array}$ & $\begin{array}{l}\text { Might be difficult to } \\
\text { produce effectively in } \\
\text { arbitrary geometries. } \\
\text { Specific concrete cover } \\
\text { needed, i.e. not suitable } \\
\text { for very thin structures }\end{array}$ \\
\hline Fibre reinforcement & $\begin{array}{l}\text { Can be added to } \\
\text { concrete during mixing. }\end{array}$ & $\begin{array}{l}\text { Rarely used as primary } \\
\text { reinforcement. }\end{array}$ \\
\hline Fibre reinforced polymer & $\begin{array}{l}\text { Good durability with } \\
\text { regards to corrosion. } \\
\text { Can be used in thin } \\
\text { concrete members. }\end{array}$ & $\begin{array}{l}\text { Affected by degradation } \\
\text { mechanisms e.g. } \\
\text { UV-light and salts. } \\
\text { Rare technology which } \\
\text { can lead to high costs. } \\
\text { Generally brittle } \\
\text { fracture. } \\
\text { Fixed shape once } \\
\text { produced. } \\
\text { Thermal expansion } \\
\text { differing from that of } \\
\text { concrete, leading to } \\
\text { restraint forces. } \\
\text { Fire resistance needs to } \\
\text { be carefully designed. }\end{array}$ \\
\hline Textile reinforcement & $\begin{array}{l}\text { Can be applied in } \\
\text { arbitrary geometries. } \\
\text { Allows for thin } \\
\text { structures. }\end{array}$ & $\begin{array}{l}\text { Restricts the concrete } \\
\text { mix design to a high } \\
\text { extent. } \\
\text { Rare technology which } \\
\text { can lead to high costs. } \\
\text { Production method } \\
\text { needs development. }\end{array}$ \\
\hline
\end{tabular}


Table 2: Summary of advantages and disadvantages with five different fibre materials.

\begin{tabular}{|c|c|c|}
\hline & Advantages & Disadvantages \\
\hline Steel fibre reinforcement & $\begin{array}{l}\text { Good mechanical } \\
\text { behaviour. } \\
\text { Very well developed. } \\
\text { Inexpensive. }\end{array}$ & $\begin{array}{l}\text { Authorities in some } \\
\text { countries (e.g. Sweden) do } \\
\text { not allow combination with } \\
\text { conventional steel } \\
\text { reinforcement in chloride } \\
\text { environment. } \\
\text { Possible corrosion spotting } \\
\text { on surfaces. }\end{array}$ \\
\hline Glass fibre reinforcement & High strength. & $\begin{array}{l}\text { Strength decreases with } \\
\text { time. } \\
\text { Sensitive to alkali attack. }\end{array}$ \\
\hline Polymer fibre reinforcement & Non-corrosive. & $\begin{array}{l}\text { Creep. } \\
\text { Elevated temperature can } \\
\text { cause problems. } \\
\text { Low Young's modulus. }\end{array}$ \\
\hline Carbon fibre reinforcement & $\begin{array}{l}\text { Alkali resistant. } \\
\text { Dimensionally stable. } \\
\text { High strength. }\end{array}$ & $\begin{array}{l}\text { Hard to obtain a good } \\
\text { distribution in concrete } \\
\text { mix }\end{array}$ \\
\hline Natural fibre reinforcement & $\begin{array}{l}\text { Available in the developing } \\
\text { world. }\end{array}$ & $\begin{array}{l}\text { Hard to ensure fibre } \\
\text { quality. } \\
\text { Hygroscopic. } \\
\text { Complex to assess } \\
\text { durability. }\end{array}$ \\
\hline
\end{tabular}

Based on this study, presented more in detail Fall and Nielsen [9], it was concluded that conventional steel reinforcement cannot easily be set aside when designing load carrying concrete structures, as none of the other reinforcement types discussed can provide such integrity in all applications. Furthermore, including conventional reinforcement also increases the applicability of the new construction concept, devised by TailorCrete, as it is well-known and regulated in standards worldwide. However, alternative reinforcement techniques, e.g. steel fibre reinforcement, can be included to control crack widths and to contribute additional structural integrity in terms of ductility.

Following this study, it was decided to continue to develop a reinforcement solution for load-bearing tailor-made concrete structures by utilizing both conventional reinforcement and steel fibre reinforcement, separately or in combination. Textile reinforcement might be interesting; however, limitations are set by the flexibility of the textile. It may, simply put, be impossible for robots to handle such material. In structural applications where corrosion is likely to cause problems, polymer fibres should be considered as an alternative. 
Glass fibre would only be suitable if thin sheet elements are to be produced.

\section{Rational design process}

To enable the use of unique concrete elements at normal price levels is the purpose of devising an automated production process. For this to be used in practice, it is also important to improve the links between architects, structural engineers and producers.

Tailor-made concrete structures are intended to be produced by means of digital fabrications, ranging from conceptual design to production [10, see Fig. 1. However, there are several obstacles to having a seamless flow of information through the entire process. In this study, the main focus is on the structural engineering part. In making a structural design of uniquely shaped specimens, the finite element method (FEM) is a powerful tool. Finite element modeling requires geometrically well-defined models, compatible with the chosen element type. At this point, the engineer needs to manually adjust the architectural model in order to obtain a structural model. An example of this could be the idealization of a solid 3D model as an FE model built with shell elements. Furthermore, the structural engineer needs either long experience or a rational digital design method for interpreting analytical results in order to design the reinforcement in a way that fulfils the requirements of both structural behaviour and production. Finally, the engineer needs to be able to forward the design to the digital fabrication tool. Traditionally, this would typically be drawings; however, digital fabrication requires a 3D model in a supported format.

It should be noted that the ability to produce concrete structures in unconventional geometries allows the architect and the designer to optimise the structure in a structural manner, which is rarely done today. However, structural optimisation is a field that has been widely researched, especially for concrete shells, during the past two decades [11, 12, [13. 


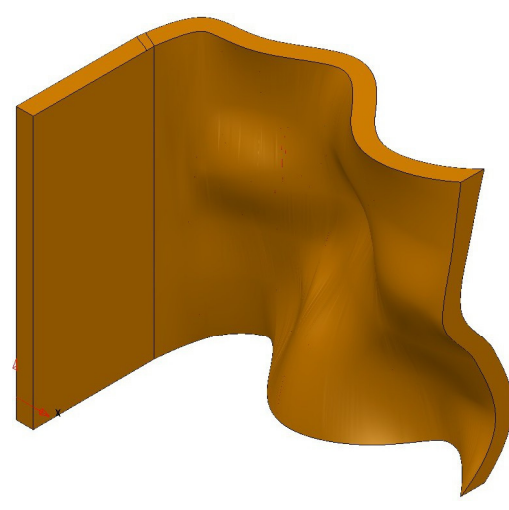

(a)

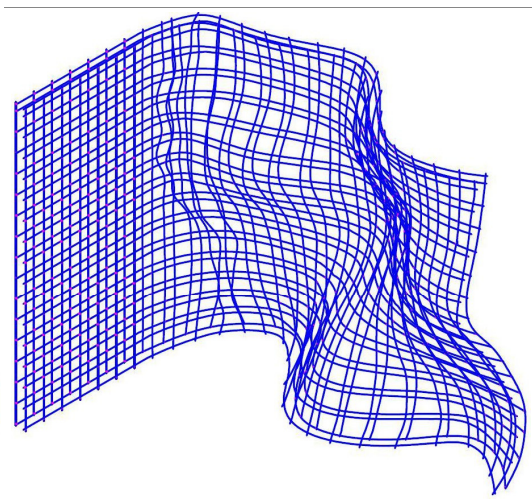

(b)

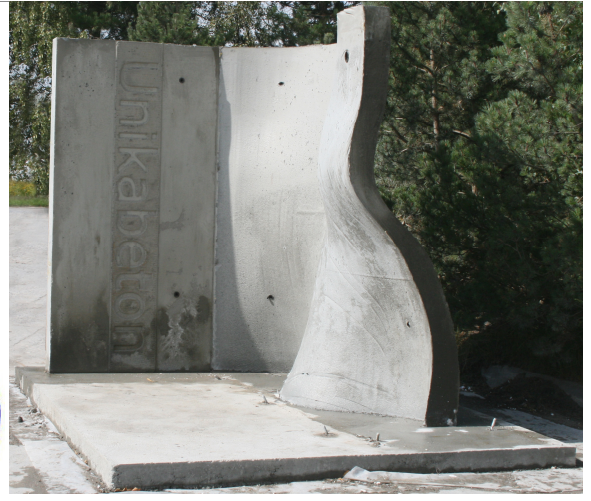

(c)

Figure 1: (a) Architectural model of prototype element and (b) the corresponding reinforcement model. (c) Manufactured (unreinforced) prototype. Photo: Thomas Juul Andersen, Teknologisk Institut (DTI)

\section{Rational design methods for conventional steel reinforcement}

Complex geometries introduce challenges not only for production but also for design. In this section, the basis for a rational design method is based on a review of available design methods for conventional steel reinforcement. Although, the complex geometry discussed in this article is arbitrary, it is reasonable to regard it as shell-like structure. For slabs and shells, plastic design methods are often utilized. From a linear finite element analysis, the linear stress state in the structure can be obtained. The design engineer can then take advantage of plastic redistributions in the cracked concrete structure, i.e. the linear stresses can be redistributed in accordance with the reinforcement design. A solution will be fulfilled as long as enough deformation capacity (ductility) is provided. In this section two alternative methods are presented and discussed. Both methods are suitable for implementation in a design tool, to aid the structural engineer working with a complex concrete structure.

In both methods, the reinforcement design starts with a linear finite element analysis, using shell elements to describe the geometry. The stress components acting in a shell element are introduced in Fig. 2. With eight independent stress resultants $\left(n_{x}, n_{y}, n_{x y}\right.$, $\left.m_{x}, m_{y}, m_{x y}, \nu_{x}, \nu_{y}\right)$, the general plain shell element, see Fig. 2, differs from a membrane element describing only the in-plane axial forces $\left(n_{i}\right)$. For curved shell elements, the components generally become coupled as equilibrium conditions involve all stress resultants [14. A way to categorize the general shell element is by considering only the non-zero stress resultants. In this manner, elements subjected to membrane action only are called membranes $\left(m_{x}=m_{y}=m_{x y}=v_{x}=v_{y}=0\right)$, elements subjected to pure bending action only $\left(n_{x}=n_{y}=n_{x y}=0\right)$ are called plates (or slabs), and elements with both types of stress components are called shells. 
When designing by the sandwich analogy, the axial forces and bending moments are accounted for in the outer layers, while the core is subjected only to the shear forces, see Fig. 3 .

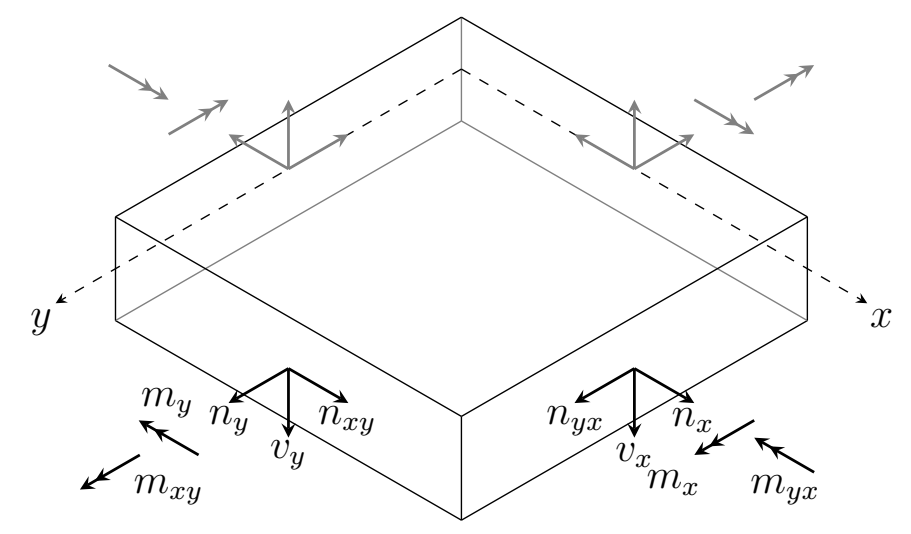

Figure 2: Plane shell element with stress components: bending and membrane action.

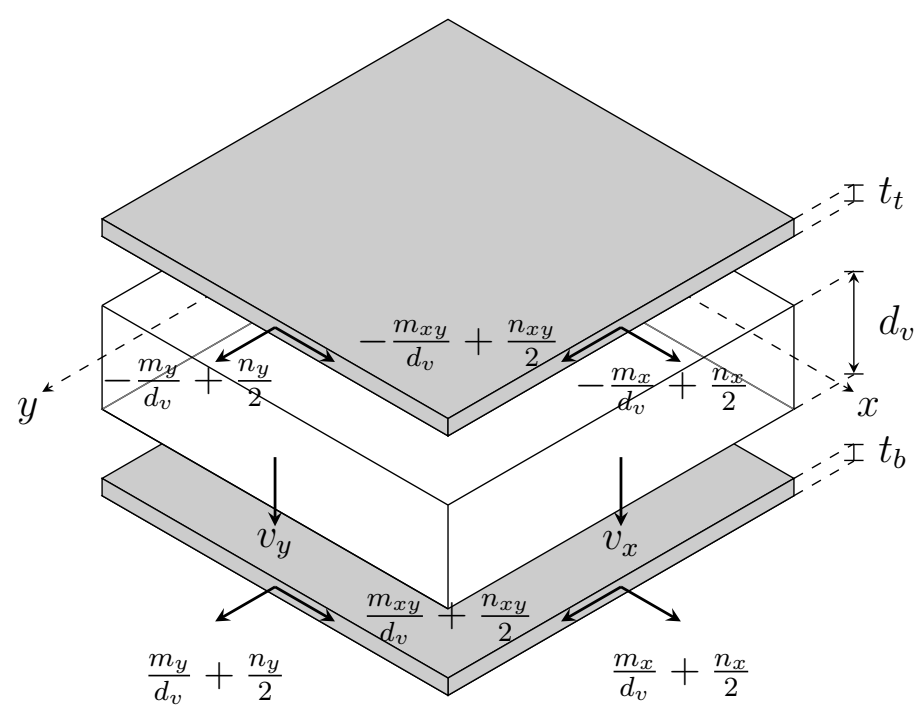

Figure 3: Sandwich model with the division of the stress resultants in Fig. 2, see also Martí [15.

\subsection{Alternative A: Simplified approach}

For the first of the two alternative methods, a simplified approach is used. This was proposed by Martí [16] and was later included in the bulletins of the International Federation for Structural Concrete (fib) [14, 17]. It is also described and exemplified in Blaauwendraad [18. The forces in the top and bottom layers are calculated as: 


$$
\begin{gathered}
n_{x, \text { layer }}= \pm \frac{m_{x}}{d_{v}}+\frac{n_{x}}{2}, \\
n_{y, \text { layer }}= \pm \frac{m_{y}}{d_{v}}+\frac{n_{y}}{2}, \\
n_{x y, \text { layer }}= \pm \frac{m_{x y}}{d_{v}}+\frac{n_{x y}}{2} .
\end{gathered}
$$

Assuming that the concrete core sustains the shear forces, without cracking, the forces in the reinforcement can be calculated as:

$$
\begin{gathered}
n_{s x b}=\frac{m_{x}}{d_{v}}+\frac{n_{x}}{2}+k_{b}\left|\frac{m_{x y}}{d_{v}}+\frac{n_{x y}}{2}\right|, \\
n_{s x t}=-\frac{m_{x}}{d_{v}}+\frac{n_{x}}{2}+k_{t}\left|-\frac{m_{x y}}{d_{v}}+\frac{n_{x y}}{2}\right|, \\
n_{s y b}=\frac{m_{y}}{d_{v}}+\frac{n_{y}}{2}+k_{b}\left|\frac{m_{x y}}{d_{v}}+\frac{n_{x y}}{2}\right|, \\
n_{s y t}=-\frac{m_{y}}{d_{v}}+\frac{n_{y}}{2}+k_{t}\left|-\frac{m_{x y}}{d_{v}}+\frac{n_{x y}}{2}\right|,
\end{gathered}
$$

where $k$ and $k^{\prime}$ are positive arbitrary factors governing the distribution of stresses between the $\mathrm{x}$ and $\mathrm{y}$ directions for the bottom and top layers respectively. The principal shear force, sustained by the concrete core, can be calculated as

$$
v_{0}=\sqrt{v_{x}^{2}+v_{y}^{2}}
$$

When the principal shear force exceeds the nominal shear cracking resistance, i.e. $v_{0}>$ $\tau_{c, r e d}$, it is assumed that the concrete core is cracked. The assumptions for transferring transversal forces, for both uncracked and cracked concrete core, can be seen in Fig. 4. If the concrete core is cracked, the shear forces also need to be added to the reinforcement forces:

$$
\begin{gathered}
n_{s x}= \pm \frac{m_{x}}{d_{v}}+\frac{n_{x}}{2}+\frac{v_{x}^{2}}{2 v_{0} \tan \theta} \\
n_{s y}= \pm \frac{m_{y}}{d_{v}}+\frac{n_{y}}{2}+\frac{v_{y}^{2}}{2 v_{0} \tan \theta} \\
n_{s x y}= \pm \frac{m_{x y}}{d_{v}}+\frac{n_{x y}}{2}+\frac{v_{x} v_{y}}{2 v_{0} \tan \theta}
\end{gathered}
$$




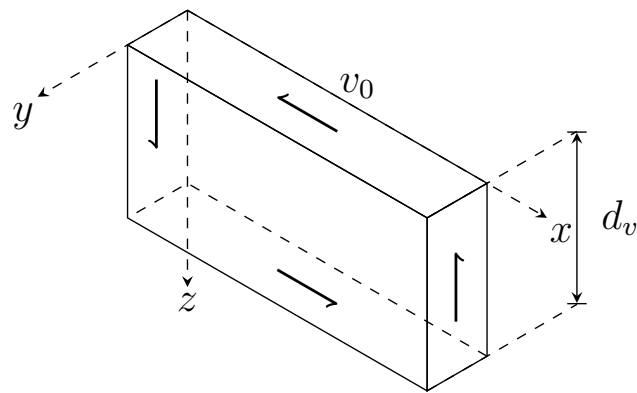

(a)

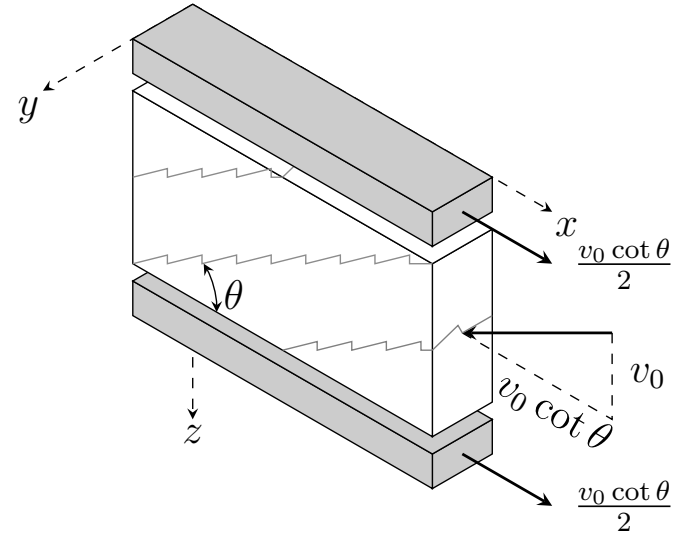

(b)

Figure 4: Transfer of transversal forces in (a) uncracked and (b) cracked core, see also Martí [15].

Denoting the reinforcement content (area per unit width) $a_{s}$ and $a_{s}^{\prime}$ and the yield strength of the reinforcement $f_{y}$, the failure governed by yielding of the reinforcement can be checked:

$$
\begin{gathered}
a_{s x b} f_{y} \geq \frac{m_{x}}{d_{v}}+\frac{n_{x}}{2}+\frac{v_{x}^{2}}{2 v_{0} \tan \theta}+k_{b}\left|\frac{m_{x y}}{d_{v}}+\frac{n_{x y}}{2}+\frac{v_{x} v_{y}}{2 v_{0} \tan \theta}\right|, \\
a_{s y b} f_{y} \geq \frac{m_{y}}{d_{v}}+\frac{n_{y}}{2}+\frac{v_{y}^{2}}{2 v_{0} \tan \theta}+k_{b}^{-1}\left|\frac{m_{x y}}{d_{v}}+\frac{n_{x y}}{2}+\frac{v_{x} v_{y}}{2 v_{0} \tan \theta}\right|, \\
a_{s x t} f_{y} \geq-\frac{m_{x}}{d_{v}}+\frac{n_{x}}{2}+\frac{v_{x}^{2}}{2 v_{0} \tan \theta}+k_{t}\left|\frac{m_{x y}}{d_{v}}+\frac{n_{x y}}{2}+\frac{v_{x} v_{y}}{2 v_{0} \tan \theta}\right|, \\
a_{s y t} f_{y} \geq-\frac{m_{y}}{d_{v}}+\frac{n_{y}}{2}+\frac{v_{y}^{2}}{2 v_{0} \tan \theta}+k_{t}^{-1}\left|\frac{m_{x y}}{d_{v}}+\frac{n_{x y}}{2}+\frac{v_{x} v_{y}}{2 v_{0} \tan \theta}\right| .
\end{gathered}
$$

For the equations above to apply it must be ensured that the outer layers of the sandwich model are not crushed. This can be taken into account by making a good choice of layer thickness (also affecting $d_{v}$ ), which can be checked:

$$
\begin{aligned}
& f_{c} t_{b} \geq a_{s x b} f_{y}+a_{s y b} f_{y}-\left(n_{x}+n_{y}\right), \\
& f_{c} t_{t} \geq a_{s x t} f_{y}+a_{s y t} f_{y}-\left(n_{x}+n_{y}\right),
\end{aligned}
$$

where $f_{c}$ is the concrete compressive strength, and $t_{b}$ and $t_{t}$ denote the thickness of the thickness of the bottom and top layers, respectively. 


\subsection{Alternative B: Advanced approach}

Alternatively, a sandwich approach suggested by Lourenco and Figueiras [19] can be used. Given that the nodal forces and bending moments are known, the reinforcement is designed with equilibrium equations. In their work, solutions are provided for cases when there is either reinforcement or no reinforcement in the top or bottom layer, or both. In the present paper, only the solution to the general example with reinforcement in both the top and bottom layers of the structure is given. Letting $n_{s x t}, n_{s x b}, n_{\text {syt }}$ and $n_{s y b}$ denote the forces resisted by the reinforcement in the $\mathrm{x}$ and $\mathrm{y}$ directions (last subscript $b$ and $t$ for bottom and top), it can be concluded that:

$$
\begin{gathered}
n_{s x}=n_{s x t}+n_{s x b}, \\
n_{s y}=n_{s y t}+n_{s y b}, \\
m_{s x}=-n_{s x t} h_{x t}+n_{s x b} h_{x b}, \\
m_{s y}=-n_{s y t} h_{y t}+n_{s y b} h_{y b},
\end{gathered}
$$

where $h_{x t}, h_{x b}, h_{y t}$ and $h_{y b}$ denote the distance from the middle of the element to the top and bottom reinforcement in the $\mathrm{x}$ and $\mathrm{y}$ direction, respectively. Letting $t_{t}$ and $t_{b}$

denote the thickness of the concrete layer with uniform stress distribution in the top and bottom layers, the concrete forces and moments can be derived as:

$$
\begin{gathered}
n_{c t}=-t_{t} f_{c d 2}, \\
m_{c t}=-\frac{1}{2}\left(h-t_{t}\right) n_{c t}, \\
n_{c b}=-t_{b} f_{c d 2}, \\
m_{c b}=\frac{1}{2}\left(h-t_{b}\right) n_{c b},
\end{gathered}
$$

where $f_{c d 2}$ denotes the compressive strength reduced due to tensile cracks parallel to the compression direction, in accordance with Comité Euro-Internacional du Béton [20]. In Eq. 18 - 25, the internal forces are expressed. Naturally, they have to be in equilibrium with the external forces and moments, i.e. the applied forces. The equilibrium conditions are presented below. From the set of six equilibrium equations, a total of eight unknowns needs to be solved, leaving the designer to choose the values on the rupture planes, $\theta_{t}$ and $\theta_{b}$, see Fig. 5, as well as the thicknesses of the outer layers, $t_{t}$ and $t_{b}$. Furthermore, the choice of $t_{t}+t_{b} \leq h$, where $h$ is the full section height, serves as a check for compressive crushing of the concrete: 


$$
\begin{gathered}
n_{x}=n_{s x}+n_{c t} \sin ^{2} \theta_{t}+n_{c b} \sin ^{2} \theta_{b}, \\
n_{y}=n_{s y}+n_{c t} \cos ^{2} \theta_{t}+n_{c b} \cos ^{2} \theta_{b}, \\
n_{x y}=-n_{c t} \sin \theta_{t} \cos \theta_{t}-n_{c b} \sin \theta_{b} \cos \theta_{b}, \\
m_{x}=m_{s x}+m_{c t} \sin ^{2} \theta_{t}+m_{c b} \sin ^{2} \theta_{b}, \\
m_{y}=m_{s y}+m_{c t} \cos ^{2} \theta_{t}+m_{c b} \cos ^{2} \theta_{b}, \\
m_{x y}=-m_{c t} \sin \theta_{t} \cos \theta_{t}-m_{c b} \sin \theta_{b} \cos \theta_{b} .
\end{gathered}
$$

Under the condition that $\theta_{t} \neq 0$ or $\pi / 2$ and $\theta_{b} \neq 0$ or $\pi / 2$, the equilibrium equations can be reformulated as:

$$
\begin{aligned}
& -n_{c t}=\frac{\left(h-t_{b}\right) n_{x y}-2 m_{x y}}{h_{c} \sin 2 \theta_{t}}, \\
& -n_{c b}=\frac{\left(h-t_{t}\right) n_{x y}-2 m_{x y}}{h_{c} \sin 2 \theta_{b}},
\end{aligned}
$$

with $h_{c}=h-\left(t_{t}-t_{b}\right) / 2$. With all eight unkowns in this system of equations solved (including the chosen values of $\theta_{b}, \theta_{t}, t_{b}$ and $t_{t}$ ), the reinforcement amount can then simply be obtained as:

$$
\begin{aligned}
& a_{s x t}=\frac{n_{s x t}}{f_{y}}, \\
& a_{s y t}=\frac{n_{s y t}}{f_{y}}, \\
& a_{s x b}=\frac{n_{s x b}}{f_{y}}, \\
& a_{s y b}=\frac{n_{s y b}}{f_{y}} .
\end{aligned}
$$

In Lourenco and Figueiras [19], an iteration scheme was proposed. In addition, they proposed the use of an optimization routine to minimize the total amount of reinforcement, suggesting the initial choices of $\theta_{t}=\theta_{b}= \pm \pi / 4$ and $a_{t}=a_{b}=0.2 h$ [19, 21]. 


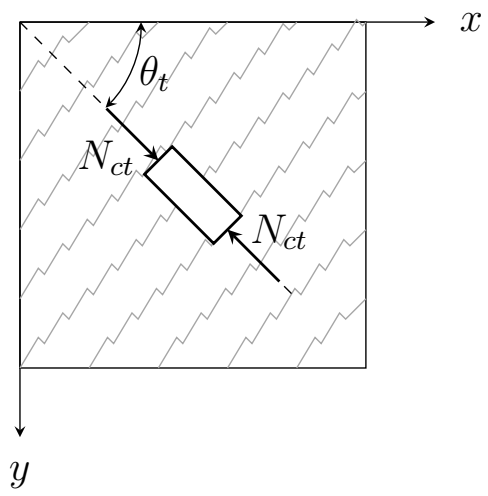

(a)

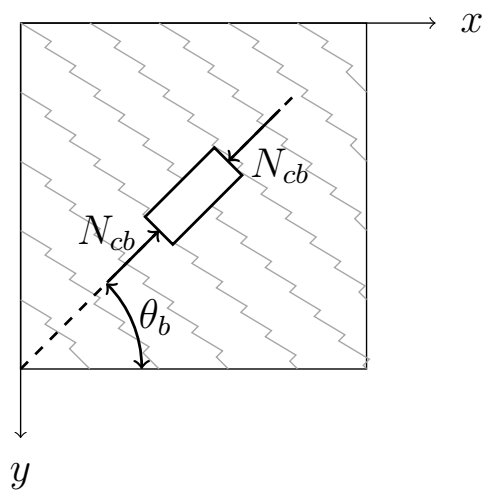

(b)

Figure 5: Crack direction and rupture plane (perpendicular) for (a) top layer and (b) bottom layer of the sandwich model, see Lourenco and Figueiras [19]

\subsection{Evaluation of the alternatives:}

The first method presented is based on several simplifications, e.g. that the resultants of the steel forces in both outer layers, act in the middle plane of these layers which is generally untrue. This might violate the equilibrium conditions. The deviation from the real lever arm tends to cause that errors increase with the increasing magnitude of twisting moments [18. However, the more advanced model presented by Lourenco and Figueiras [19] is more demanding; it needs to be solved with iterative procedures.

Lourenco and Figueiras [19] give a numerical example. The same example was calculated in this study with the simplified method, see the appendix. The results are shown in Tab. 3. For the simplified method, it was assumed that $d_{v}=h_{x t}+h_{x b}=h_{y t}+h_{y b}$ and $k=k^{\prime}=1$. The example does not include shear forces, therefore the concrete core was assumed to be uncracked. It was also assumed that reinforcement was needed in both top and bottom layers. The following input was used:

$$
\begin{gathered}
n_{x}=-200 \mathrm{kN} / \mathrm{m}, \quad n_{y}=300 \mathrm{kN} / \mathrm{m}, \quad n_{x y}=75 \mathrm{kN} / \mathrm{m}, \\
m_{x}=-60 \mathrm{kNm} / \mathrm{m}, \quad m_{y}=40 \mathrm{kNm} / \mathrm{m}, \quad m_{x y}=-20 \mathrm{kNm} / \mathrm{m}, \\
h=0.2 \mathrm{~m}, \quad h_{x}=h_{y t}=h_{x b}=h_{y b}=0.08 \mathrm{~m}, \\
f_{c d}=13.3 \mathrm{MPa}, \quad f_{c d 2}=7.34 \mathrm{MPa}, \quad f_{y}=348 \mathrm{MPa} .
\end{gathered}
$$


Table 3: Numerical results

\begin{tabular}{lrrr}
\hline & Simplified method & $\begin{array}{l}\text { Advanced method, } \\
\text { iterative [19] }\end{array}$ & $\begin{array}{l}\text { Advanced method, } \\
\text { optimized [19] }\end{array}$ \\
\hline$\theta_{t}$ & - & $45.0^{\circ}$ & $45.6^{\circ}$ \\
\hline$\theta_{b}$ & - & $-79.6^{\circ}$ & $-78.9^{\circ}$ \\
\hline$a_{\text {sxt }}$ & $11.14 \mathrm{~cm}^{2} / \mathrm{m}$ & $15.14 \mathrm{~cm}^{2} / \mathrm{m}$ & $14.63 \mathrm{~cm}^{2} / \mathrm{m}$ \\
\hline$a_{\text {syt }}$ & $0.36 \mathrm{~cm}^{2} / \mathrm{m}$ & $2.27 \mathrm{~cm}^{2} / \mathrm{m}$ & $2.08 \mathrm{~cm}^{2} / \mathrm{m}$ \\
\hline$a_{\text {sxb }}$ & $12.57 \mathrm{~cm}^{2} / \mathrm{m}$ & $1.00 \mathrm{~cm}^{2} / \mathrm{m}$ & $0.00 \mathrm{~cm}^{2} / \mathrm{m}$ \\
\hline$a_{\text {syb }}$ & $16.16 \mathrm{~cm}^{2} / \mathrm{m}$ & $12.14 \mathrm{~cm}^{2} / \mathrm{m}$ & $12.15 \mathrm{~cm}^{2} / \mathrm{m}$ \\
\hline Total & $40.23 \mathrm{~cm}^{2} / \mathrm{m}$ & $30.55 \mathrm{~cm}^{2} / \mathrm{m}$ & $28.86 \mathrm{~cm}^{2} / \mathrm{m}$ \\
\hline
\end{tabular}

In this example, the advanced model provided a more efficient reinforcement solution, in terms of total reinforcement amount. It should be pointed out that the solution with the least reinforcement is not necessarily the best with regard to production. Limitations in production can affect the minimum bar spacing, number of layers and dimensions of bars. Such factors need to be included in possible future rational design methods for tailor-made concrete structures. If the methods discussed here are applied to an arbitrary design, the choice of axis direction might not be obvious. This yields one further parameter to be changed in order to find the best solution.

An issue that is not treated in the two methods described is the increased need for tensile force capacity due to inclined shear cracking. The maximum reinforcement amount would not be affected, since that is situated where the shear force is zero; however, inclined shear cracking does affect the amount of reinforcement needed in all of the other parts. In the design of more complex concrete structures, the increased need for tensile reinforcement due to inclined shear cracking must be included in a rational fashion.

Furthermore, in concrete structures with complex geometries, it may be possible to reinforce some areas with steel fibre reinforcement only. It would then be beneficial to add a design procedure for this in a rational design process, as well as aids for detecting such areas, based on geometrical factors (e.g. section height and geometric complexity) and linear stress analysis.

When a reinforcement design has been performed, the behaviour of the composite can be studied with non-linear finite element analysis, as reported by e.g. Min and Gupta [22] and Noh [23].

\section{Conclusions}

Based on the work presented in this paper the following conclusions can be drawn:

- The benefits of using conventional steel reinforcement bars are many. As there are standards, structures can be built without any additional approvals. The performance has been studied for a long time and the material is inexpensive. 
- Steel fibre reinforcement has good properties when it comes to structural application. By introducing steel fibres into the concrete, the ductility is increased and serviceability is improved in terms of smaller crack widths.

- Neither fibre reinforced polymers nor textile reinforcement appears to be applicable in practise for production with industrial robots. Fibre reinforced polymer bars cannot be formed after production and the current production methods for textile reinforcement are closely associated with either craftsmanship or a highly industrialized process applicable only to very large series.

- To handle complex reinforced concrete design rationally, software connections need to be developed, especially when applying automated production processes.

- To ensure a solution that fulfils equilibrium and has more efficient reinforcement distribution, the advanced approach is preferred. Hence, for a future design tool the more advanced model should be used.

- The increased need for tensile force capacity, due to inclined shear cracking, is not included in either of the two methods described. This needs to be included in a rational fashion in the design of more complex reinforced concrete structures.

- In a future design tool for the reinforcement of concrete structures with complex geometry, there is a need not only for optimization of the amount of reinforcement, but also for optimization to fit the requirements of the production method.

\section{Acknowledgements}

This research were funded by the European Community's Seventh Framework Programme under grant agreement NMP2-LA-2009-228663 (TailorCrete). More information on the project TailorCrete can be found at www.tailorcrete.com.

\section{Notations}

$a_{s x b}$ Reinforcement amount in bottom layer, $\mathrm{x}$ direction

$a_{s x t}$ Reinforcement amount in top layer, x direction

$a_{\text {syb }}$ Reinforcement amount in bottom layer, y direction

$a_{\text {syt }}$ Reinforcement amount in top layer, y direction

$d_{v} \quad$ Height of the concrete core

$f_{c} \quad$ Compressive strength of concrete

$f_{c d 2} \quad$ Compressive strength of concrete, reduced due to cracking

$f_{y} \quad$ Yielding strength of reinforcement

$h \quad$ Height of the sandwich model cross section

$h_{x b} \quad$ Distance from centre plane to bottom layer, $\mathrm{x}$ direction 


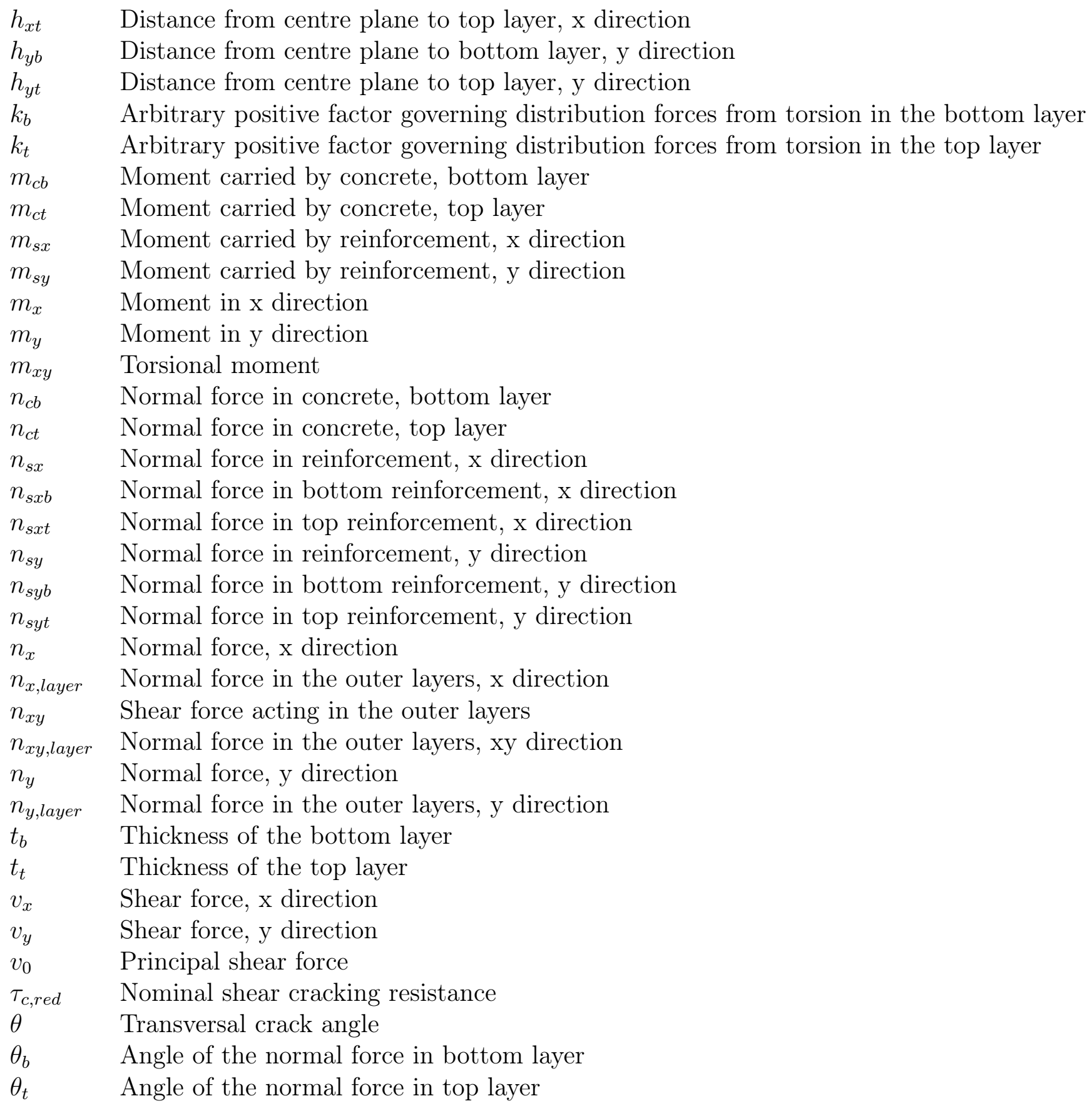

[1] Cortsen J, Jørgensen JA, Sølvason D, Petersen HG. Simulating robot handling of large scale deformable objects: Manufacturing of unique concrete reinforcement structures. Accepted by the International Conference of ICRA, St.Paul, Minnesota, USA; 2012.

[2] Bentur A, Mindess S. Fibre reinforced cementitious composites. New York: Taylor \& Francis; 2nd edn. ed.; 2007.

[3] Oslejs J. New frontiers for steel fiber-reinforced concrete. Concr Int 2008;30(5):45-50. 
[4] Dejke V. Durability of FRP Reinforcement in Concrete. Ph.D. thesis; Department of Building Materials, Chalmers University of Technology, Gothenburg, Sweden; 2001.

[5] Karlsson M. Rapport 9803: Fiberkompositarmering. Gothenburg, Sweden: FoU-Väst; 1998. ISBN 1402-7410.

[6] Bisby LA, Green MF, Kodur VKR. Response to fire of concrete structures that incorporate frp. Progress in Structural Engineering and Materials 2005;7(3):136-49. doi: \bibinfo $\{$ doi $\}\{10.1002 /$ pse.198\}. URL http://dx.doi.org/10.1002/pse.198.

[7] Brameshuber W. State-of-the-Art Report of RILEM Technical Committee 201-TRC. Bagneux, France: RILEM Publications S.A.R.L; 2006.

[8] Sun W, Chen H, Luo X, Qian H. The effect of hybrid fibers and expansive agent on the shrinkage and permeability of high-performance concrete. Cement Concr Res 2001;31(4):595-601.

[9] Fall D, Nielsen C. Concrete reinforcement solutions. Report 2010:7; Division of Structural Engineering, Department of Civil and Environmental Engineering, Chalmers University of Technology, Gothenburg, Sweden; 2010.

[10] Williams N, Stehling H, Scheuer F, Oesterle S, Kohler M, Gramazio F. A Case Study of a Collaborative Digital Workflow in the Design and Production of Formwork for "Non-Standard" Concrete Structures. 2011. Accepted for publication in Int J Architect Comput.

[11] Tomás A, Martí P. Shape and size optimisation of concrete shells. Eng Struct 2010;32(6):1650-8.

[12] Ramm E, Mehlhorn G. On shape finding methods and ultimate load analyses of reinforced concrete shells. Eng Struct 1991;13(2):178 -98.

[13] Vizotto I. Computational generation of free-form shells in architectural design and civil engineering. Automat Constr 2010;19(8):1087 -105.

[14] International Federation for Structural Concrete (fib) . Bulletin 45: Practitioners' guide to finite element modelling of reinforced concrete structures. CEB/FIP; 2008.

[15] Martí P. Dimensioning and detailing. In: IABSE Reports; vol. 62. IABSE Colloquium Stuttgart; 1991, p. 411-43.

[16] Martí P. Design of concrete slabs for transverse shear. ACI Struct J 1990;87(2):180-90.

[17] International Federation for Structural Concrete (fib) . Bulletin 55-56: Model Code 2010 First Complete Draft. CEB/FIP; 2010.

[18] Blaauwendraad J. Plates and FEM: Suprises and Pitfalls. Heidelberg, Germany: Springer; 2010. ISBN 978-90-481-3595-0. 
[19] Lourenco PB, Figueiras JA. Automatic design of reinforcement in concrete plates and shells. Eng Computations 1993;10(6):519-41.

[20] Comité Euro-Internacional du Béton . Ceb-fip Model Code 1990. CEB/FIP; 1993.

[21] Lourenco PB, Figueiras JA. Solution for the design of reinforced concrete plates and shells. J Struct Eng-ASCE 1995;121(6):815-23.

[22] Min CS, Gupta AK. Inelastic behaviour of reinforced concrete hyperbolic paraboloid saddle shell. Eng Struct 1994;16(4):227 -37.

[23] Noh HC. Nonlinear behavior and ultimate load bearing capacity of reinforced concrete natural draught cooling tower shell. Eng Struct 2006;28(3):399 - 410. 


\section{Appendix: Calculation of an example with the simplified method}

Given:

$$
\begin{gathered}
n_{x}=-200 \mathrm{kN} / \mathrm{m}, \quad n_{y}=300 \mathrm{kN} / \mathrm{m}, \quad n_{x y}=75 \mathrm{kN} / \mathrm{m}, \\
m_{x}=-60 \mathrm{kNm} / \mathrm{m}, \quad m_{y}=40 \mathrm{kNm} / \mathrm{m}, \quad m_{x y}=-20 \mathrm{kNm} / \mathrm{m}, \\
h=0.2 \mathrm{~m}, \quad h_{x}=h_{y t}=h_{x b}=h_{y b}=0.08 \mathrm{~m}, \\
f_{c d}=13.3 \mathrm{MPa}, \quad f_{c d 2}=7.34 \mathrm{MPa}, \quad f_{y}=348 \mathrm{MPa} .
\end{gathered}
$$

Assuming there is no shear cracking, reinforcement is needed in both directions in both layers and $d_{v}=h_{x t}+h_{x b}=h_{y t}+h_{y b}=0.16 \mathrm{~m}$, the forces translated to the layers become:

$$
\begin{gathered}
n_{x, \text { layer }}= \pm \frac{m_{x}}{d_{v}}+\frac{n_{x}}{2}= \pm \frac{-60 * 10^{3}}{0.16}+\frac{-200 * 10^{3}}{2}= \pm 375 * 10^{3}-100 * 10^{3} \mathrm{~N} / \mathrm{m}, \\
n_{x t}=-475 \mathrm{kN} / \mathrm{m}, \quad n_{x b}=275 \mathrm{kN} / \mathrm{m}, \\
n_{y, \text { layer }}= \pm \frac{m_{y}}{d_{v}}+\frac{n_{y}}{2}= \pm \frac{40 * 10^{3}}{0.16}+\frac{300 * 10^{3}}{2}= \pm 250 * 10^{3}+150 * 10^{3} \mathrm{~N} / \mathrm{m}, \\
n_{y t}=-100 \mathrm{kN} / \mathrm{m}, \quad n_{y b}=400 \mathrm{kN} / \mathrm{m}, \\
n_{x y, \text { layer }}= \pm \frac{m_{x y}}{d_{v}}+\frac{n_{x y}}{2}= \pm \frac{-20 * 10^{3}}{0.16}+\frac{75 * 10^{3}}{2}= \pm 125 * 10^{3}+37.5 * 10^{3} \mathrm{~N} / \mathrm{m}, \\
n_{x y t}=-87.5 \mathrm{kN} / \mathrm{m}, \quad n_{x y b}=162.5 \mathrm{kN} / \mathrm{m} .
\end{gathered}
$$

Using $k=k^{\prime}=1$, the forces resisted by the reinforcement are given by:

$$
\begin{gathered}
n_{s x b}=\frac{m_{x}}{d_{v}}+\frac{n_{x}}{2}+k\left|\frac{m_{x y}}{d_{v}}+\frac{n_{x y}}{2}\right| n_{s x b}=275 * 10^{3}+k\left|162.5 * 10^{3}\right|=437.5 \mathrm{kN} / \mathrm{m} \\
n_{s x t}=-\frac{m_{x}}{d_{v}}+\frac{n_{x}}{2}+k^{\prime}\left|-\frac{m_{x y}}{d_{v}}+\frac{n_{x y}}{2}\right| n_{s x t}=-475 * 10^{3}+k^{\prime}|-87.5|=-387.5 \mathrm{kN} / \mathrm{m} \\
n_{s y b}=\frac{m_{y}}{d_{v}}+\frac{n_{y}}{2}+k\left|\frac{m_{x y}}{d_{v}}+\frac{n_{x y}}{2}\right| n_{s y b}=400+k|162.5|=562.5 \mathrm{kN} / \mathrm{m}
\end{gathered}
$$




$$
n_{s y t}=-\frac{m_{y}}{d_{v}}+\frac{n_{y}}{2}+k^{\prime}\left|-\frac{m_{x y}}{d_{v}}+\frac{n_{x y}}{2}\right| n_{s y t}=-100+k^{\prime}|-87.5|=-12.5 \mathrm{kN} / \mathrm{m} .
$$

Using $f_{y}=348 \mathrm{MPa}$, the reinforcement area per unit width can be obtained as:

$$
\begin{aligned}
& a_{s x b}=\frac{437.5 * 10^{3}}{348 * 10^{6}}=0.001257 \mathrm{~m}^{2} / \mathrm{m}=12.57 \mathrm{~cm}^{2} / \mathrm{m} \\
& a_{s x t}=\frac{-387.5 * 10^{3}}{348 * 10^{6}}=0.001114 \mathrm{~m}^{2} / \mathrm{m}=11.14 \mathrm{~cm}^{2} / \mathrm{m} \\
& a_{s y b}=\frac{562.5 * 10^{3}}{348 * 10^{6}}=0.001616 \mathrm{~m}^{2} / \mathrm{m}=16.16 \mathrm{~cm}^{2} / \mathrm{m} \\
& a_{s y t}=\frac{-12.5 * 10^{3}}{348 * 10^{6}}=0.000036 \mathrm{~m}^{2} / \mathrm{m}=0.36 \mathrm{~cm}^{2} / \mathrm{m}
\end{aligned}
$$

